\title{
Genetic and Epigenetic Regulation of Stem Cell Homeostasis in Plants
}

\author{
M. LODHA, C.F. Marco, AND M.C.P. Timmermans \\ Cold Spring Harbor Laboratory, Cold Spring Harbor, New York 11724
}

\begin{abstract}
Plants generate new organs through the activity of small populations of stem cells present in specialized niches called meristems. Stem cell homeostasis is attained by dynamic regulatory networks involving transcriptional regulators, hormones, and other intercellular signals that specify cell fate and convey positional information to the apical stem cells and the organizing center located immediately below. The balance between stem cell maintenance within the shoot apical meristem (SAM) and differentiation of cells that are displaced from the niche to form new organs involves the epigenetic silencing of stem cell regulatory genes. Recent advances have identified highly conserved chromatin remodeling factors as epigenetic regulators of stem cell fate that confer plasticity in plant development and ensure the stable inheritance of repressed expression states during organogenesis. These advances reveal that common mechanisms contribute to stem cell homeostasis in plants and animals.
\end{abstract}

One of the fundamental differences between plant and animal development is that plants produce new organs throughout their lifetime, which can span hundreds of years. This reiterative process of organogenesis depends on the activity of populations of pluripotent stem cells present in specialized niches, termed meristems, at the growing tip of the root and shoot (Fig. 1). Despite their common functions in stem cell maintenance and organ formation, the root and shoot meristems are organized differently. In the root, a single layer of stem cells surrounds an organizing center comprised of a small group of infrequently dividing cells that signal to the adjoining stem cells to inhibit their differentiation (van den Berg et al. 1997; Jiang and Feldman 2005). Each stem cell divides asymmetrically, giving rise to one daughter cell that main- tains stem cell identity through contact with the organizing center and one daughter that is displaced from the niche and differentiates.

The angiosperm SAM consists of a small dome of cells that is organized into central and peripheral zones, distinguished by cell division rates and gene expression patterns. In the SAM of the model plant Arabidopsis, approximately three stem cells are maintained in each of the three most apical cell layers in the central zone $(\mathrm{CZ})$ of the meristem (Fig. 1C) (see Bäurle and Laux 2003; Williams and Fletcher 2005). Their pluripotency is maintained by signals from an organizing center located immediately below the stem cell cluster. Thus, in contrast to the root, direct contact with the organizing center is not required to acquire or maintain shoot stem cell identity. Following stem cell divi-
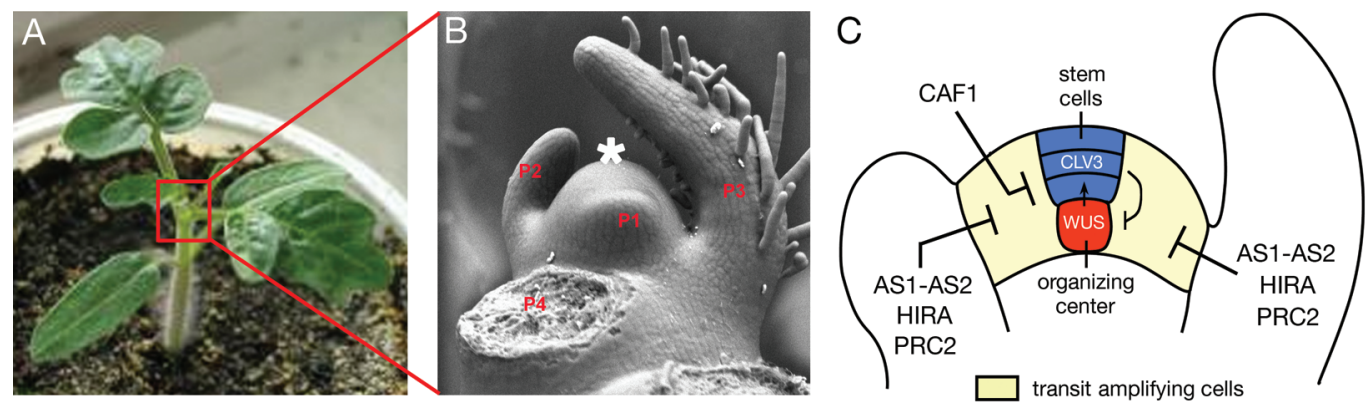

Figure 1. The shoot stem cell niche. $(A)$ The shoot stem cell niche or meristem is located at the growing tip of the plant. The approximate position is indicated on this tomato seedling by the red box. (B) A scanning electron micrograph shows close-up of a tomato apex. (Asterisk) The shoot apical meristem. Stem cell activity leads to the periodic formation of new differentiating organs, such as the leaves shown here (marked P1-P4). (C) Diagram of the shoot stem cell niche. Stem cells are located in the central zone at the most apical tip (blue) overlaying the organizing center (red). WUS is expressed in the organizing center. WUS is required to maintain the pluripotent state of the overlying stem cells and to activate CLV3 expression in these cells. CLV3 signaling in turn restricts the WUS expression domain. WUS expression is further regulated by the chromatin assembly factor CAF1. Stem cells give rise to a population of transit-amplifying cells (yellow) on the meristem periphery from which differentiating leaves are formed. KNOX genes are expressed in the central zone and transit-amplifying cells, but following organ initiation, $K N O X$ genes are maintained in a repressed chromatin state through the action of AS1, AS2, HIRA, and PRC2. (B, Kindly provided by C. Kuhlemeier; $C$, modified from Tucker and Laux 2007.) 
sion, one of the daughter cells typically enters a zone of indeterminate transit-amplifying cells at the meristem periphery (PZ), from which differentiating lateral organs are periodically initiated. Superimposed on the organization of the SAM into central and peripheral zones are discrete lineage layers. Cells in the outermost L1 divide anticlinally and give rise to the epidermal layer. Cells of the L2 also form a single layer that gives rise mostly to mesophyll tissue, and the innermost L3 comprises multiple cell layers that form the internal tissues, including mesophyll and vasculature. Predictably, the shoot stem cell cluster overlaps with each of these lineage layers (Fig. 1C).

During the past 5 years, mechanistic models for root and shoot meristem development have begun to emerge (see Sablowski 2007; Scheres 2007; Tucker and Laux 2007; Dinneny and Benfey 2008). Gene regulatory networks involved in stem cell specification and patterning of the root and shoot stem cell niches during embryogenesis have been identified. Important advances have also been reported on the signaling pathways that operate within these stem cell niches to maintain stem cell homeostasis and coordinate organogenesis. In this review, we describe regulatory networks that control stem cell activity within the vegetative shoot apex, focusing first on key genetic pathways involved in maintaining stem cell homeostasis within the SAM and subsequently on the molecular mechanisms that repress stem cell fate upon commitment to differentiation.

\section{REGULATION OF STEM CELL HOMEOSTASIS BY THE WUS-CLV FEEDBACK LOOP}

The homeodomain transcription factor WUSCHEL (WUS) is expressed exclusively in the organizing center of the SAM and is required to maintain the pluripotent state of the overlying stem cells, such that in plants that lack WUS activity, these stem cells undergo differentiation (Fig. 1C) (Laux et al. 1996; Mayer et al. 1998). In contrast to the root meristem, cell division patterns in and around the shoot organizing center are not predictable, and cells at the SAM tip are continuously displaced during shoot growth. Nonetheless, the position and size of the WUS expression domain remain remarkably constant throughout the life of the plant. WUS expression thus appears to be dynamically regulated and continuously redefined by positional information within the shoot. In support of this idea, a new organizing center can be established de novo after laser ablation of the CZ (Reinhardt et al. 2003a).

Not surprisingly, several regulatory genes that spatially define the domain of WUS expression during various stages of plant development have been identified, e.g., $H A N A B A$ TARANU, STIMPY/WOX9, HAIRY MERISTEM, AGAMOUS, ULTRAPETELA, the HD-ZIPIII genes, and possibly APETELA2 (Lenhard et al. 2001; Stuurman et al. 2002; Zhao et al. 2004; Carles et al. 2005; Prigge et al. 2005; Williams et al. 2005; Wu et al. 2005; Würschum et al. 2006). In addition to these transcription factors, WUS expression appears to be regulated epigenetically through recruitment of the SNF2 chromatin-remodeling factor SPLAYED and perhaps indirectly by small RNAs (Kwon et al. 2005). In the absence of functional PINHEAD/ZWILLE
(PNH/ZLL), a member of the ARGONAUTE family of small RNA-induced silencing factors, the WUS expression domain is enlarged (Moussian et al. 1998; Lynn et al. 1999; Tucker et al. 2008). Expression of PNH/ZLL from a vascular-specific promoter can rescue the shoot meristem phenotype of $\mathrm{pnh} / \mathrm{zll}$ mutants, suggesting that the basal stem region may provide positional information to regulate $W U S$ activity (Tucker et al. 2008).

The WUS expression domain is further defined by a positional signal from the overlying stem cells in the $C Z$ via the CLAVATA (CLV) signaling pathway. In response to WUSdependent signaling, the stem cells not only remain undifferentiated, but also induce expression of CLV3 (Fig. 1C). The CLV3 gene encodes a small protein that is processed into a secreted 12-amino-acid peptide (Fletcher et al. 1999; Kondo et al. 2006). Similar to plants overexpressing the CLV3 gene, application of this 12-amino-acid peptide onto shoot apices terminates meristem activity, indicating that it constitutes the active CLV3 ligand. This ligand is perceived via the CLV1-CLV2 receptor kinase complex, which is expressed in a region that overlaps with the organizing center, and, via negative regulation of the POLTERGEIST (POL) and POL-like 1 phosphatases, down-regulates WUS expression (Fig. 1C) (Carles and Fletcher 2003; Song et al. 2006). This feedback loop between the organizing center and the stem cells creates a self-regulatory system to maintain a near constant size of the stem cell population (Brand et al. 2000; Schoof et al. 2000).

WUS induces stem cell identity in the overlying tissue layers in part by regulating cytokinin signaling. Many classical studies had demonstrated a role for cytokinin in promoting cell cycle activity and shoot identity. More recent studies provide the first insights into how cytokinin signaling is regulated in the SAM to control meristem function. Arabidopsis plants, in which cytokinin signaling is perturbed through mutation of the three known cytokinin receptors CYTOKININ RESPONSE1 (CRE1), ARABIDOPSIS HISTIDINE KINASE2 (AHK2), and $A H K 3$, display a reduction in shoot meristem size (Higuchi et al. 2004). Likewise, mutations in the rice gene LONELY GUY (LOG), which encodes a cytokinin biosynthetic enzyme, reduce meristem size (Kurakawa et al. 2007). $L O G$ is expressed near the tip of the SAM, suggesting that localized cytokinin production near the $\mathrm{CZ}$ is important for stem cell maintenance. One of the outcomes of cytokinin signaling is the activation of A-type ARABIDOPSIS RESPONSE REGULATORS (ARR) that provide negative feedback regulation and thus dampen the intracellular cytokinin response (for review, see Müller and Sheen 2007). Using chromatin immunoprecipitation (ChIP) coupled to microarray analyses, Leibfried et al. (2005) identified several A-type $A R R$ genes, including $A R R 5$ and $A R R 7$, as direct targets of repression by WUS. However, $A R R 7$ is expressed in the SAM, in a region that roughly coincides with the expression domain of WUS. This suggests that WUS modulates ARR7 levels and the cytokinin response. In plants that express a constitutively active from of ARR7, the stem cell population is depleted (Liebfried et al. 2005). In contrast, mutations in the maize A-type RESPONSE REGULATOR abphyll lead to an increase in meristem size (Giulini et al. 2004). Together, 
these studies reveal that stem cell homeostasis requires a precisely defined cytokinin signaling response that is attained in part through the local repression of A-type ARR activity by WUS.

\section{REGULATION OF STEM CELL ACTIVITY BY KNOX HOMEODOMAIN PROTEINS}

In parallel to the WUS-CLV signaling pathway, class I KNOTTED1-like homeodomain (KNOX) proteins are key regulators of stem cell homeostasis in the plant shoot (Endrizzi et al. 1996; Long et al. 1996). In Arabidopsis, the class I KNOX gene family includes SHOOT MERISTEMLESS (STM), BREVIPEDICELLUS (BP) (also known as KNAT1), KNAT2, and KNAT6. These genes have distinct but overlapping expression patterns within the SAM that reflect their diverse partially redundant activities in stem cell maintenance and organogenesis. STM is expressed in both the central and peripheral zones of the SAM, whereas expression of $B P$ and $K N A T 2$ is confined to the periphery of the meristem (Lincoln et al. 1994; Long et al. 1996; Pautot et al. 2001). The expression domains reported for class I KNOX genes of other plant species similarly correspond to one of two general patterns. Like STM, maize knotted1 $(k n 1)$, tomato LeT6, and tobacco NTH1 are expressed in both the central and peripheral zones of the SAM, whereas expression of the class I KNOX genes rough sheath1 ( $r s 1)$ and gnarlyl $(g n l)$ of maize, osh15 of rice, and NTH2O of tobacco is limited to the basal region of the SAM's peripheral zone (for references, see Reiser et al. 2000; Scofield and Murray 2006).

Loss-of-function mutations in STM and $k n 1$ give rise to embryos that lack a SAM and so fail to develop any postembryonic vegetative tissues (Barton and Poethig 1993; Long et al. 1996; Vollbrecht et al. 2000). Even though $b p$ single mutants have no obvious SAM defects, $B P$ is conditionally redundant with $S T M$ and, in certain genetic backgrounds, can functionally replace STM in the maintenance of the shoot stem cell niche (Byrne et al. 2002). A role for other class I KNOX genes in stem cell homeostasis has been inferred from overexpression studies. Expression of all KNOX genes is down-regulated in leaf founder cells and, in simple leafed species, such as Arabidopsis, rice, and maize, typically remains repressed throughout organogenesis (see, e.g., Jackson et al. 1994; Lincoln et al. 1994; Long et al. 1996). Ectopic expression of $K N O X$ genes in developing primordia interferes with organ differentiation and patterning. In Arabidopsis, KNOX misexpression causes the development of highly dissected or lobed leaves (Lincoln et al. 1994; Chuck et al. 1996; Brand et al. 2002). Depending on the severity of the phenotype, shoot meristems can form de novo in the sinuses between the lobes or on the upper leaf surface. In monocots, ectopic KNOX expression leads to the overproliferation of cells and the displacement of proximal tissue types into the distal leaf blade (see Hake et al. 2004). On the basis of these recessive and dominant phenotypes, KNOX genes have been implicated in maintaining proliferation of stem cells and transit-amplifying cells in the SAM and/or preventing their differentiation.

The activities of KNOX genes in stem cell homeostasis are closely entwined with several plant hormone pathways. A number of recent studies reveal a link also between $K N O X$ activity and cytokinin. As mentioned above, the size of the shoot stem cell niche is reduced in mutants that perturb cytokinin biogenesis or signaling (Higuchi et al. 2004; Kurakawa et al. 2007). Conversely, the shoot meristem defects of stm mutants can be suppressed by increasing the level of cytokinin, whether through application of exogenous hormone or overexpression of ISOPENTENYL TRANSFERASE (IPT) genes, which encode an enzyme in the cytokinin biosynthetic pathway (Yanai et al. 2005). Moreover, STM and KNAT2 were shown to positively regulate $I P T 7$, and ectopic $K N O X$ expression leads to increased accumulation of cytokinin and up-regulation of the cytokinin-induced response regulators $A R R 5$ and $A R R 7$ (Jasinski et al. 2005; Yanai et al. 2005). Because gibberelic acid (GA) signaling antagonizes cytokinin signaling, KNOX genes further promote the cytokinin pathway by negatively regulating the expression of GA-20 oxidase, a key GA biosynthetic enzyme, in the SAM (Sakamoto et al. 2001; Hay et al. 2002). Thus, it is conceivable that KNOX genes contribute to stem cell activity at least in part by promoting cytokinin accumulation in the meristem. However, the various cell types of the SAM may well respond differently to cytokinin. Whereas KNOX genes promote expression of the negative response regulators $A R R 5$ and $A R R 7$, WUS represses their expression (Leibfried et al. 2005). Future studies will tell whether local differences in cytokinin signaling contribute to partitioning of the meristem into regions containing stem cells, the organizing center, or transit-amplifying cells.

Down-regulation of $K N O X$ gene expression is required for the specification of organ initials from transit-amplifying cells on the flank of the SAM (Jackson et al. 1994; Long et al. 1996). Sites of organ initiation are further defined by local accumulation of the hormone auxin (Reinhardt et al. 2000, 2003b). An antagonistic relationship between auxin and $K N O X$ activity could provide a mechanism for the required down-regulation in $K N O X$ expression associated with organogenesis. Indirect evidence for such a link is presented by the misexpression of BP in Arabidopsis plants carrying mutations in genes involved in auxin transport or signaling (Hay et al. 2006). However, how the local accumulation of auxin might trigger the repression of $K N O X$ genes is not currently understood.

\section{NEGATIVE REGULATORS OF KNOX GENE EXPRESSION}

As is evident from the marked developmental defects observed in simple leaves that ectopically express $K N O X$ genes, their normal progression to differentiation requires that KNOX activity remains repressed throughout organogenesis. This process is mediated by the orthologous MYB-domain proteins ROUGH SHEATH2 (RS2), ASYMMETRIC LEAVES1 (AS1), and PHANTASTICA from maize, Arabidopsis, and Antirrhinum, respectively (Timmermans et al. 1999; Tsiantis et al. 1999; Byrne et al. 2000; Ori et al. 2000). These proteins are expressed in a pattern complementary to the KNOX genes, in organ 
founder cells and developing primordia, but not within the meristem proper. Loss-of-function mutations in $r s 2$ and $A S 1$ lead to perturbations in cell determination typical of ectopic $K N O X$ accumulation (Fig. 2). However, the downregulation of $K N O X$ genes at the site of leaf initiation is unaffected in these mutants, indicating that RS2 and AS1 act after organ initiation to maintain $K N O X$ genes silenced during subsequent leaf development. Expression studies have shown that multiple $K N O X$ genes, including $k n l$ and $r s 1$, are misexpressed in leaves of $r s 2$ mutants (Schneeberger et al. 1998; Scanlon et al. 2002; Alexander et al. 2005; Evans 2007). In Arabidopsis, BP and KNAT2 are targets for negative regulation by $A S 1$ (Byrne et al. 2000; Ori et al. 2000; Semiarti et al. 2001). However, expression of $S T M$ is unaffected in as 1. In fact, $S T M$ appears to repress $A S 1$ expression (Byrne et al. 2000).

Additional mutations that lead to KNOX misexpression in developing leaves have been identified. These include semaphore 1 and corkscrewl in maize and asymmetric leaves2 (as2), blade-on-petiole1, and yabby3 filamentous

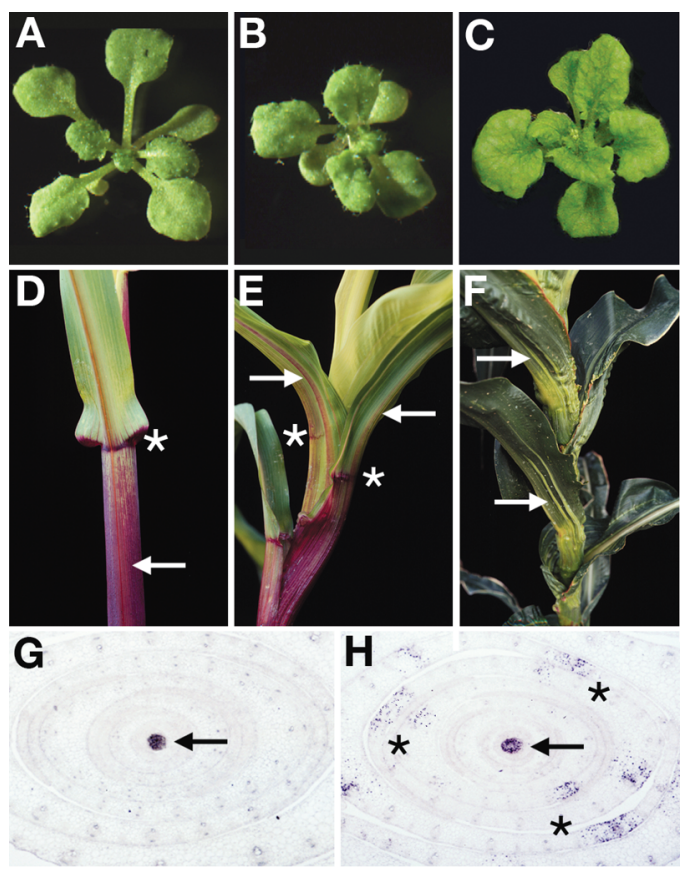

Figure 2. $K N O X$ expression in developing leaf primordia interferes with organ differentiation and patterning. $(A)$ Image of a wild-type Arabidopsis plant. (B) Compared to wild type, as 1 plants are more compact and as 1 leaves are smaller, asymmetrically lobed, and have a rough leaf surface. $(C)$ Mutants with reduced $H I R A$ activity develop as 1-like defects in cell proliferation and differentiation. (D) Normal maize leaves develop a sharp boundary between proximal sheath (arrow) and distal blade regions, as marked by the asterisk. (E) Mutations in $r s 2$ affect proximodistal patterning of the leaf, as indicated by a disruption of the sheath-blade boundary (asterisks) and sectors of sheath tissue extending distally into the leaf blade (arrows). $(F)$ Mature rs 2 leaves develop a rough sheath due to the overproliferation of cells. Arrows mark sectors of sheath tissue in the leaf blade. $(G, H)$ Immunolocalization of KNOX proteins in transverse sections of wild-type $(G)$ and $r s 2$ null mutant apices $(H)$. KNOX proteins accumulate in the SAM of both wild-type and $r s 2$ mutant plants (arrows). In addition, sectors expressing KNOX proteins are present in $r s 2$ leaves (asterisks). flower double mutants in Arabidopsis. Some of these mutants likely have an indirect effect on KNOX gene expression. For instance, mutations in semaphorel cause pleiotropic defects in the kernel and seedling that are associated with altered auxin transport (Scanlon et al. 2002), and ectopic KNOX expression in the yabby3 filamentous flower double mutant is associated with defects in adaxialabaxial leaf polarity (Kumaran et al. 2002). AS2, on the other hand, functions with AS1 in a common genetic pathway. The Arabidopsis as 2 mutant has leaf phenotypes comparable to as 1 that are associated with the misexpression of $B P$ and KNAT2, and like as1, as 2 can suppress the stm mutant phenotype (Ori et al. 2000; Semiarti et al. 2001; Byrne et al. 2002; Lin et al. 2003). AS2 is a member of the LBD family of transcription factors, which contain a highly conserved amino-terminal zinc finger and leucinezipper-like motif, and has been shown to physically interact with AS1 (Iwakawa et al. 2002; Shuai et al. 2002; Phelps-Durr et al. 2005; Husbands et al. 2007). Likewise, RS2 interacts physically with the maize homolog of AS2 (Phelps-Durr et al. 2005), presenting the possibility that $K N O X$ gene silencing during organogenesis involves a mechanism that is conserved between monocot and dicot simple leafed species, which last shared a common ancestor approximately 100 million years ago.

Insight into the mechanism by which AS1 and AS2 repress $K N O X$ genes and establish determinacy came from a recent study by Guo et al. (2008), which showed that these proteins form a repressor complex that binds directly to two sites in the promoters of $B P$ and KNAT2. A repressor activity for AS1 was demonstrated by fusing its carboxy-terminal non-MYB domain to the DNA-binding domain of the floral regulator LEAFY (LFY). Expression of this fusion protein from the native $L F Y$ promoter leads to the repression of LFY targets giving rise to characteristic lfy loss-offunction phenotypes. Binding of an AS1 complex to the promoters of $B P$ and $K N A T 2$ was demonstrated using ChIP. Both KNOX promoters contain at least two AS1-complexbinding sites. Electrophoretic mobility-shift assays revealed that complex binding at each site is mediated by the regulatory motif arrangement CWGTTD-KMKTTGAHW and requires interaction between $\mathrm{AS} 1$ and $\mathrm{AS} 2$. Interestingly, deletion of either AS1-complex-binding site in $B P$ results in ectopic expression in developing leaves, indicating that the two sites act nonredundantly despite their analogous AS1AS2-binding properties. Accordingly, interaction between AS1 complexes at each site appears to be required, suggesting that a repressive loop may be formed in the $K N O X$ promoters that mediates stable KNOX gene silencing during organogenesis (Guo et al. 2008). The observation that AS1 can form homodimers (Theodoris et al. 2003; Phelps-Durr et al. 2005) presents a possible mechanism via which AS1 complexes can interact. Promoter deletion analysis further revealed that enhancer elements required for $B P$ expression in the leaf are located between the AS1-AS2 complex binding sites. On the basis of these observations, it was proposed that AS1 and AS2 maintain KNOX gene silencing via a mechanism that is conceptually similar to the action of insulators that form chromatin loop domains that sequester enhancer elements and block their action on promoters (Gaszner and Felsenfeld 2006). 


\section{EPIGENETIC REGULATION OF PLANT STEM CELL FATE}

Cellular memory is a general feature of development. Transcriptional outputs resulting from early cell-fate decisions need to be stably maintained throughout many rounds of cell division. In plants and animals, several epigenetic regulators have been identified that ensure the stable inheritance of activated or repressed expression states at developmental loci. The pattern of ectopic KNOX accumulation in $r s 2$ leaves provided a first indication that the stable repression of KNOX genes during organogenesis involves an epigenetic cellular memory system. In $r s 2$, $K N O X$ genes become reactivated in a variable variegated pattern, such that $r s 2$ null leaves are clonal mosaics of $K N O X^{+}$and $K N O X^{-}$sectors (Fig. 2G,H) (Timmermans et al. 1999). This pattern of $K N O X$ reactivation is reminiscent of the variegated expression patterns resulting from a failure to stably maintain a repressive chromatin state in all cells of a lineage. Sectors of $K N O X$ reactivation are not observed in as 1. Deletion of AS1-AS2-binding sites or loss of AS1or AS2 function results in ectopic expression of $B P$ and KNAT2 throughout young leaf primordia and in the petiole region and vasculature of older leaves (Ori et al. 2000; Guo et al. 2008). KNOX gene silencing in Arabidopsis thus has a stricter requirement for AS1. Nonetheless, AS1-AS2-mediated KNOX gene silencing may similarly involve an epigenetic maintenance mechanism. The expression domains of AS1 and AS2 overlap only in the very young leaf primordia (Iwakawa et al. 2007), indicating that $K N O X$ misexpression in older leaves is unlikely a direct reflection of lost AS1-AS2complex activity. An epigenetic mechanism for repressing stem cell fate in differentiating organs allows stem cell pluripotency to be reprogrammed during later stages of plant development and facilitates the somatic regeneration of plants upon wounding or in culture.

Consistent with an epigenetic mode of KNOX gene repression during leaf development, AS1 and RS2 interact with the chromatin-remodeling factor HIRA (Phelps-Durr et al. 2005). This WD-repeat protein is highly conserved throughout evolution. The yeast and animal HIRA proteins promote the DNA-synthesis-independent assembly of nucleosomes and can modulate chromatin structure both during heterochromatic gene silencing and to control the spatial and temporal expression of specific euchromatic genes (Spector et al. 1997; Magnaghi et al. 1998; Sharp et al. 2001; Ray-Gallet et al. 2002; Tagami et al. 2004; Zhang et al. 2005; Nakayama et al. 2007). Interestingly, in mouse, HIRA functions in the epigenetic regulation of stem cell pluripotency as well as in the reprogramming of expression states upon cellular differentiation (Meshorer et al. 2006; Hajkova et al. 2008). In Arabidopsis, hira null mutants are early embryonic lethal. However, in plants with reduced HIRA function, BP and KNAT2 are reactivated in developing leaves, and such plants develop as 1-like defects in cell proliferation and differentiation (Fig. 2C) (PhelpsDurr et al. 2005). This presents the likely possibility that the AS1-AS2-mediated recruitment of HIRA to the $B P$ and KNAT2 promoters leads to formation of a repressive chromatin state that is stably inherited throughout the many rounds of cell division associated with leaf development (Guo et al. 2008).

HIRA shares homology with the p60 subunit of the chromatin assembly factor 1 (CAF1) complex (PhelpsDurr et al. 2005). Interestingly, CAF1 also has an important role in maintaining stem cell homeostasis. Mutations in the Arabidopsis FASCIATA1 (FAS1) or FAS2 genes, which encode the p150 and p60 components of CAF1, respectively, lead to fasciation of the stem and enlargement and flattening of the SAM (Kaya et al. 2001). In addition, the functional organization of the SAM in distinct central and peripheral zones is severely disrupted in fas mutants. FAS1 and FAS2 affect meristem organization and function by regulating the size of the WUS expression domain, which in fas mutants is dispersed and expanded laterally and apically. Expression of WUS and CLV3 is unaffected in weak hira mutants (C. Fernandez-Marco and M. Timmermans, unpubl.), suggesting that HIRA and CAF1 regulate meristem function and organogenesis through independent pathways.

The involvement of CAF1, rather then HIRA, in regulating WUS expression is particularly intriguing considering that asymmetric cell divisions are key to defining the WUS expression domain and limiting the size of the stem cell population in the shoot (Mayer et al. 1998; see Scheres 2007). Both HIRA and CAF1 are nucleosome assembly factors. However, whereas HIRA can function independently of DNA synthesis, CAF1 is associated with proliferating cell nuclear antigen (PCNA) at the replication fork and assembles nucleosomes in a DNA-synthesisdependent manner (Ray-Gallet et al. 2002; Tagami et al. 2004). Although chromatin states are normally inherited by both daughter cells, it has long been recognized that DNA replication provides a window of opportunity for changes in chromatin structure that might affect gene expression. The inherent asymmetry of the replication fork with a leading and lagging strand leads to a temporary asymmetric distribution of PCNA among the sister chromatids (Shibahara and Stillman 1999; Zhang et al. 2000). Because CAF1 binds to PCNA to direct chromatin assembly after DNA replication, this situation offers an opportunity for the establishment of an asymmetric chromatin structure on the two sister chromatids before division of proliferating cells (Shibahara and Stillman 1999; Zhang et al. 2000). Such an asymmetric distribution of epigenetic information, if inherited by the daughter cells, could provide the foundation for phenotypic asymmetry in sister cells during development that could perhaps allow one cell to maintain WUS expression or stem cell identity and the other cell to change cell fate.

As in animal systems, Polycomb group $(\mathrm{PcG})$ proteins also have an important role in stem cell homeostasis in Arabidopsis (Katz et al. 2004; Boyer et al. 2006; Lee et al. 2006; Schubert et al. 2006; Pietersen and van Lohuizen 2008). These proteins form multiple evolutionary conserved complexes, termed Polycomb repressive complexes (PRCs). Animals contain two biochemically distinct PRCs. PRC2, which contains four core componentsSuppressor-of-Zeste12 (Su[z]12), Enhancer-of-Zeste (E[z]), Extra-Sex-Comb (Esc), and p55/RbAp48 - catalyzes the trimethylation of histone H3 lysine 27 (H3K27) 
(Lund and van Lohuizen 2004; Schwartz and Pirrotta 2007). This chromatin mark provides a binding site for PRC1, which establishes a condensed chromatin structure that maintains genes stably silenced.

The PRC2 is structurally conserved in plants (see Makarevich et al. 2006; Schubert et al. 2006; Pien and Grossniklaus 2007). The Arabidopsis CURLY LEAF (CLF), $M E D E A(M E A)$, and SWINGER (SWN) genes encode homologs of E[z]; FERTILIZATION-INDEPENDENT SEED2 (FIS2), VERNALIZATION2 (VRN2), and EMBRYONIC FLOWER2 (EMF2) encode Su[z]12 homologs; FERTILIZATION-INDEPENDENT ENDOSPERM (FIE) is a homolog of Esc; and MULTICOPY SUPPRESSOR OF IRA1(MSI1) is homologous to p55/RbAp48. Data obtained from expression analyses, ChIPs, and protein-protein interaction studies indicate that multiple PRC2s contribute to the stable repression of KNOX genes during leaf development (Katz et al. 2004; Schubert et al. 2006; M. Lodha and M. Timmermans, unpubl.). CLF, MSI1, FIE, and EMF2 or VRN2 form a PRC2 that confines expression of STM to the SAM (Gendall et al. 2001; Chanvivattana et al. 2004; Schubert et al. 2006). CLF binds to STM in developing leaves and, similar to $\mathrm{E}[\mathrm{z}]$, catalyzes the trimethylation of H3K27. H3K27me3 levels at STM are dramatically decreased in clf loss-of-function mutants and STM is misexpressed in differentiating $c l f$ leaves. CLF may act partially redundant with SWN, because the H3K27me3 marks at STM are lost completely in the clf swn double mutants. Interestingly, loss of this repressive histone mark is associated with gain of $\mathrm{H} 3 \mathrm{~K} 4$ dimethylation, which is typically associated with actively transcribed genes. Gain of this histone mark suggests the involvement of a Trithorax-like complex in the derepression of STM.

The PRC1 appears to be unique to animals. In plants, LIKE HETEROCHROMATIC PROTEIN1 (LHP1) is suggested to perform an analogous function (Turck et al. 2007; Zhang et al. 2007). LHP1 contains a chromodomain and chromoshadow domain and is homologous to yeast swi6 and Heterochromatic Protein1 (HP1) in animals. Similar to PRC1, LHP1 binds to trimethylated H3K27 (Turck et al. 2007; Zhang et al. 2007). We have recently shown that CLF-based PRCs also maintain the stable repression of
$B P$ and KNAT2 during leaf development (M. Lodha and M. Timmermans, unpubl.). LHP1 localizes to repressed $B P$ and KNAT2 loci and both genes are derepressed in leaves of $\operatorname{lhp} 1$ mutants. This presents the possibility that LHP1 is recruited to these KNOX loci by H3K27 trimethylation and, like PRC1, functions in long-term memory of a repressed chromatin state.

One key outstanding question in the mammalian stem cell field is how PRCs are recruited to their target loci. Interestingly, our recent observations indicate that HIRA acts upstream of PRC2. In weak hira mutant leaves, nucleosomes at $B P$ and KNAT2 remain enriched for active chromatin marks and lack H3K27me3. These changes in chromatin modifications are not just observed around the AS1-complex-binding sites but occur throughout the KNOX loci, suggesting that stable KNOX gene silencing involves the spreading of epigenetic chromatin modifications. In chicken, HIRA interacts directly with p55/RbAp48 (Ahmad et al. 2003, 2005), suggesting the exciting possibility that HIRA can mediate the recruitment of PRC2 to target loci. If so, this presents the following working model for the stable repression of stem cell activity during organogenesis (Fig. 3): HIRA through interaction with AS1-AS2 binds the promoters of $K N O X$ targets; this facilitates the recruitment of PRC2, perhaps through direct interaction between MSI1 and HIRA; PRC2-mediated trimethylation of H3K27 subsequently recruits LHP1, which through a currently unknown mechanism leads to a stable repressive chromatin state at the $K N O X$ loci that allows cellular differentiation.

\section{CONCLUSION}

Networks of regulatory genes and intercellular signals maintain stem cell homeostasis in the plant shoot. The transcription factors that maintain the pluripotent state of stem cells function at least partly by regulating the activity of plant hormones, such as cytokinin. Local cell-cell communication among the organizing center, stem cells, and their immediate derivatives creates a self-regulatory system to maintain a near constant size of the stem cell population. Although the nature of the stem-cell-maintaining

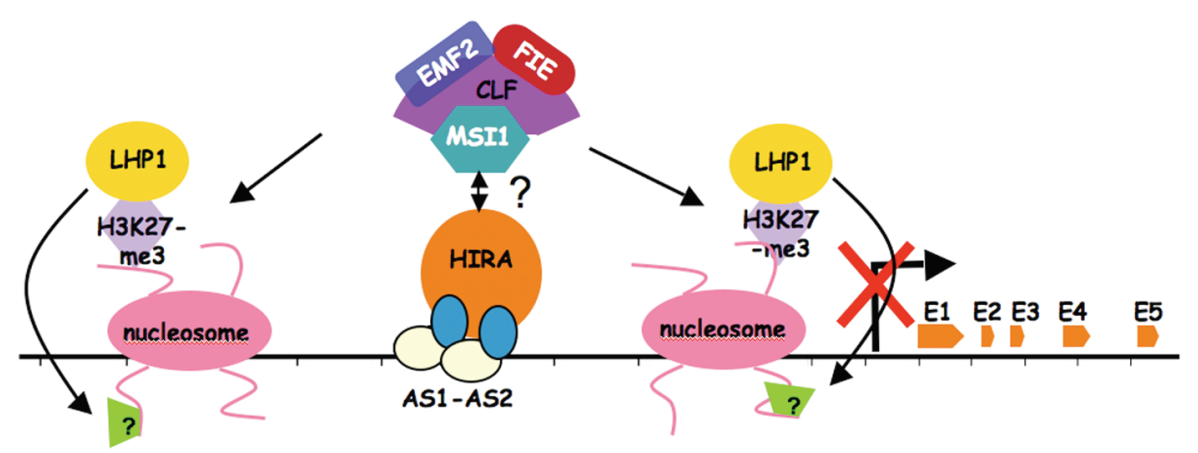

Figure 3. Model for stable $K N O X$ gene silencing in differentiating leaves. AS1-AS2 binds to two sites in the promoters of $B P$ and $K N A T 2$ and recruits HIRA to these $K N O X$ targets. Recruitment of HIRA is required for the trimethylation of $\mathrm{H} 3 \mathrm{~K} 27$ in nucleosomes at $B P$ and $K N A T 2$ by a CLF-containing PRC2. In chicken, HIRA interacts directly with the MSI1 homolog p55/Rbp48, presenting the possibility that HIRA functions to recruit PRC2 to $B P$ and $K N A T 2$. PRC2-mediated trimethylation of H3K27 subsequently recruits LHP1, which, through a currently unknown mechanism, leads to a stable repressive chromatin state at the KNOX loci that allows cellular differentiation. 
signal from the organizing center remains elusive, recent advances have revealed an active peptide ligand that regulates stem cell number. On organ initiation, epigenetic silencing mechanisms suppress stem cell fate to allow the progression of normal development. As in animal systems, HIRA and PRC2 are part of a cellular memory system that facilitates differentiation through the stable repression of stem cell regulators. The possibility that the DNAbinding proteins AS1-AS2 via interaction with HIRA recruit PRC2 to the $K N O X$ genes provides a molecular mechanism for silencing stem cell fate and could provide a framework for the recruitment of PcG complexes to target loci during the epigenetic regulation of pluripotency in animals.

\section{ACKNOWLEDGMENTS}

The authors thank past and present members of the Timmermans lab for discussions and input, especially Tara Phelps-Durr and Mengjuan Guo. Work on the epigenetic regulation of $K N O X$ gene expression in the laboratory of M.T. is supported by grants from the National Science Foundation (MCB-0616114) and NYSTEM (C023044), and C.M. is funded by a postdoctoral fellowship from the Spanish Ministry of Education and Science (2007-0937).

\section{REFERENCES}

Ahmad, A., Takami, Y., and Nakayama, T. 2003. WD dipeptide motifs and LXXLL motif of chicken HIRA are necessary for transcription repression and the latter motif is essential for interaction with histone deacetylase-2 in vivo. Biochem. Biophys. Res. Commun. 312: 1266-1272.

Ahmad, A., Kikuchi, H., Takami, Y., and Nakayama, T. 2005. Different roles of N-terminal and C-terminal halves of HIRA in transcription regulation of cell cycle-related genes that contribute to control of vertebrate cell growth. J. Biol. Chem. 280: 32090-32100.

Alexander, D.L., Mellor, E.A., and Langdale, J.A. 2005. CORKSCREW1 defines a novel mechanism of domain specification in the maize shoot. Plant Physiol. 138: 1396-1408.

Barton, M. and Poethig, S. 1993. Formation of the shoot apical meristem in Arabidopsis thaliana: An analysis of development in the wild type and in the shoot meristemless mutant. Development 119: 823-831.

Bäurle, I. and Laux, T. 2003. Apical meristems: The plant's fountain of youth. Bioessays 25: 961-970.

Boyer, L.A., Plath, K., Zeitlinger, J., Brambrink, T., Medeiros, L.A., Lee, T.I., Levine, S.S., Wernig, M., Tajonar, A., Ray, M.K., et al. 2006. Polycomb complexes repress developmental regulators in murine embryonic stem cells. Nature 441: 349-353.

Brand, U., Grünewald, M., Hobe, M., and Simon, R. 2002. Regulation of $C L V 3$ expression by two homeobox genes in Arabidopsis. Plant Physiol. 129: 565-575.

Brand, U., Fletcher, J.C., Hobe, M., Meyerowitz, E.M., and Simon, R. 2000. Dependence of stem cell fate in Arabidopsis on a feedback loop regulated by CLV3 activity. Science 289: 617-619.

Byrne, M.E., Simorowski, J., and Martienssen, R.A. 2002. ASYMMETRIC LEAVES1 reveals knox gene redundancy in Arabidopsis. Development 129: 1957-1965.

Byrne, M.E., Barley, R., Curtis, M., Arroyo, J.M., Dunham, M., Hudson, A., and Martienssen, R.A. 2000. ASYMMETRIC LEAVES1 mediates leaf patterning and stem cell function in Arabidopsis. Nature 408: 967-971.

Carles, C.C. and Fletcher, J.C. 2003. Shoot apical meristem maintenance: The art of a dynamic balance. Trends Plant Sci. 8: $394-401$.
Carles, C.C., Choffnes-Inada, D., Reville, K., Lertpiriyapong, K., and Fletcher, J.C. 2005. ULTRAPETALA1 encodes a SAND domain putative transcriptional regulator that controls shoot and floral meristem activity in Arabidopsis. Development 132: 897-911.

Chanvivattana, Y., Bishopp, A., Schubert, D., Stock, C., Moon, Y.H., Sung, Z.R., and Goodrich J. 2004. Interaction of Polycomb-group proteins controlling flowering in Arabidopsis. Development 131: 5263-5276.

Chuck, G., Lincoln, C., and Hake, S. 1996. KNAT1 induces lobed leaves with ectopic meristems when overexpressed in Arabidopsis. Plant Cell 8: 1277-1289.

Dinneny, J.R. and Benfey, P.N. 2008. Plant stem cell niches: Standing the test of time. Cell 132: 553-557.

Endrizzi, K., Moussian, B., Haecker, A., Levin, J.Z., and Laux, T. 1996. The SHOOT MERISTEMLESS gene is required for maintenance of undifferentiated cells in Arabidopsis shoot and floral meristems and acts at a different regulatory level than the meristem genes WUSCHEL and ZWILLE. Plant J. 10: 967-979.

Evans, M.M. 2007. The indeterminate gametophytel gene of maize encodes a LOB domain protein required for embryo sac and leaf development. Plant Cell 19: 46-62.

Fletcher, J.C., Brand, U., Running, M.P., Simon, R., and Meyerowitz, E.M. 1999. Signaling of cell fate decisions by CLAVATA3 in Arabidopsis shoot meristems. Science 283: 1911-1914.

Gaszner, M. and Felsenfeld, G. 2006. Insulators: Exploiting transcriptional and epigenetic mechanisms. Nat. Rev. Genet. 7: 703-713.

Gendall, A.R., Levy, Y.Y., Wilson, A., and Dean, C.D. 2001. The VERNALIZATION2 gene mediates the epigenetic regulation of vernalization in Arabidopsis. Cell 107: 525-535.

Giulini, A., Wang, J., and Jackson, D. 2004 . Control of phyllotaxy by the cytokinin-inducible response regulator homologue ABPHYL1. Nature 430: 1031.

Guo, M., Thomas, J., Collins, G., and Timmermans, M.C. 2008. Direct repression of KNOX loci by the ASYMMETRIC LEAVESI complex of Arabidopsis. Plant Cell 20: 48-58.

Hajkova, P., Ancelin, K., Waldmann, T., Lacoste, N., Lange, U.C., Cesari, F., Lee, C., Almouzni, G., Schneider, R., and Surani, M.A. 2008. Chromatin dynamics during epigenetic reprogramming in the mouse germ line. Nature 452: 877-881.

Hake, S., Smith, H.M., Holtan, H., Magnani, E., Mele, G., and Ramirez, J. 2004. The role of knox genes in plant development. Annu. Rev. Cell Dev. Biol. 20: 125-151.

Hay, A., Barkoulas, M., and Tsiantis, M. 2006. ASYMMETRIC LEAVES1 and auxin activities converge to repress $B R E$ VIPEDICELLUS expression and promote leaf development in Arabidopsis. Development 133: 3955-3961.

Hay, A., Kaur, H., Phillips, A., Hedden, P., Hake, S., and Tsiantis, M. 2002. The gibberellin pathway mediates KNOTTED1-type homeobox function in plants with different body plans. Curr. Biol. 12: $1557-1565$.

Higuchi, M., Pischke, M.S., Mähönen, A.P., Miyawaki, K., Hashimoto, Y., Seki, M., Kobayashi, M., Shinozaki, K., Kato, T., Tabata, S., et al. 2004. In planta functions of the Arabidopsis cytokinin receptor family. Proc. Natl. Acad. Sci. 101: $8821-8826$.

Husbands, A., Bell, E.M., Shuai, B., Smith, H.M., and Springer, P.S. 2007. LATERAL ORGAN BOUNDARIES defines a new family of DNA-binding transcription factors and can interact with specific bHLH proteins. Nucleic Acids Res. 35: 66636671.

Iwakawa, H., Iwasaki, M., Kojima, S., Ueno, Y., Soma, T., Tanaka, H., Semiarti, E., Machida, Y., and Machida, C. 2007. Expression of the ASYMMETRIC LEAVES2 gene in the adaxial domain of Arabidopsis leaves represses cell proliferation in this domain and is critical for the development of properly expanded leaves. Plant J. 51: 173-184.

Iwakawa, H., Ueno, Y., Semiarti, E., Onouchi, H., Kojima, S., Tsukaya, H., Hasebe, M., Soma, T., Ikezaki, M., Machida, C., and Machida, Y. 2002. The ASYMMETRIC LEAVES2 gene of Arabidopsis thaliana, required for formation of a symmetric 
flat leaf lamina, encodes a member of a novel family of proteins characterized by cysteine repeats and a leucine zipper. Plant Cell Physiol. 43: 467-478.

Jackson, D., Veit, B., and Hake, S. 1994. Expression of maize KNOTTED1 related homeobox genes in the shoot apical meristem predicts patterns of morphogenesis in the vegetative shoot. Development 120: 405-413.

Jasinski, S., Piazza, P., Craft, J., Hay, A., Woolley, L., Rieu, I., Phillips, A., Hedden, P., and Tsiantis, M. 2005. KNOX action in Arabidopsis is mediated by coordinate regulation of cytokinin and gibberellin activities. Curr. Biol. 15: 15601565.

Jiang, K. and Feldman, L.J. 2005. Regulation of root apical meristem development. Annu. Rev. Cell Dev. Biol. 21: 485509.

Katz, A., Oliva, M., Mosquna, A., Hakim, O., and Ohad, N. 2004. FIE and CURLY LEAF polycomb proteins interact in the regulation of homeobox gene expression during sporophyte development. Plant J. 37: 707-719.

Kaya, H., Shibahara, K.I., Taoka, K.I., Iwabuchi, M., Stillman, B. and Araki, T. 2001. FASCIATA genes for chromatin assembly factor-1 in Arabidopsis maintain the cellular organization of apical meristems. Cell 104: 131-142.

Kondo, T., Sawa, S., Kinoshita, A., Mizuno, S., Kakimoto, T., Fukuda, H., and Sakagami, Y. 2006. A plant peptide encoded by $C L V 3$ identified by in situ MALDI-TOF MS analysis. Science 313: 845-848.

Kumaran, M.K., Bowman, J.L., and Sundaresan, V. 2002. YABBY polarity genes mediate the repression of KNOX homeobox genes in Arabidopsis. Plant Cell 14: 2761.

Kurakawa, T., Ueda, N., Maekawa, M., Kobayashi, K., Kojima, M., Nagato, Y., Sakakibara, H., and Kyozuka, J. 2007. Direct control of shoot meristem activity by a cytokinin activating enzyme. Nature 445: 652-655.

Kwon, C.S., Chen, C., and Wagner, D. 2005. WUSCHEL is a primary target for transcriptional regulation by SPLAYED in dynamic control of stem cell fate in Arabidopsis. Genes Dev. 19: 992-1003.

Laux, T., Mayer, K.F., Berger, J., and Jürgens, G. 1996. The WUSCHEL gene is required for shoot and floral meristem integrity in Arabidopsis. Development 122: 87-96.

Lee, T.I., Jenner, R.G., Boyer, L.A., Guenther, M.G., Levine, S.S., Kumar, R.M., Chevalier, B., Johnstone, S.E., Cole, M.F., Isono, K., et al. 2006. Control of developmental regulators by Polycomb in human embryonic stem cells. Cell 125: 301-313.

Leibfried, A., To, J.P., Busch, W., Stehling, S., Kehle, A., Demar, M., Kieber, J.J., and Lohmann, J.U. 2005. WUSCHEL controls meristem function by direct regulation of cytokinin-inducible response regulators. Nature 438: 1172-1175.

Lenhard, M., Bohnert, A., Jürgens, G., and Laux, T. 2001. Termination of stem cell maintenance in Arabidopsis floral meristems by interactions between WUSCHEL and AGAMOUS. Cell 105: 805-814.

Lin, W.C., Shuai, B., and Springer, P.S. 2003. The Arabidopsis LATERAL ORGAN BOUNDARIES-domain gene ASYMMETRIC LEAVES2 functions in the repression of KNOX gene expression and in adaxial-abaxial patterning. Plant Cell 15: 2241-2252.

Lincoln, C., Long, J., Yamaguchi, J., Serikawa, K., and Hake, S. 1994. A knottedl-like homeobox gene in Arabidopsis is expressed in the vegetative meristem and dramatically alters leaf morphology when overexpressed in transgenic plants. Plant Cell 6: 1859-1876.

Long, J.A., Moan, E.I., Medford, J.I., and Barton, M.K. 1996. A member of the KNOTTED class of homeodomain proteins encoded by the STM gene of Arabidopsis. Nature 379: 66-69.

Lund, A.H. and van Lohuizen, M. 2004. Polycomb complexes and silencing mechanisms. Curr. Opin. Cell Biol. 16: 239246.

Lynn, K., Fernandez, A., Aida, M., Sedbrook, J., Tasaka, M., Masson, P., and Barton, M.K. 1999. The PINHEAD/ZWILLE gene acts pleiotropically in Arabidopsis development and has overlapping functions with the ARGONAUTE1 gene. Development 126: 469-481.
Magnaghi, P., Roberts, C., Lorain, S., Lipinski, M., and Scambler, P.J. 1998. HIRA, a mammalian homologue of Saccharomyces cerevisiae transcriptional co-repressors, interacts with Pax3. Nat. Genet. 20: 74-77.

Makarevich, G., Leroy, O., Akinci, U., Schubert, D., Clarenz, O., Goodrich, J., Grossniklaus, U., and Köhler, C. 2006. Different Polycomb group complexes regulate common target genes in Arabidopsis. EMBO Rep. 7: 947-952.

Mayer, K.F., Schoof, H., Haecker, A., Lenhard, M., Jürgens, G., and Laux, T. 1998. Role of WUSCHEL in regulating stem cell fate in the Arabidopsis shoot meristem. Cell 95: 805-815.

Meshorer, E., Yellajoshula, D., George, E., Scambler, P.J., Brown, D.T., and Misteli, T. 2006. Hyperdynamic plasticity of chromatin proteins in pluripotent embryonic stem cells. Dev. Cell 10: $105-116$

Moussian, B., Schoof, H., Haecker, A., Jürgens, G., and Laux, T. 1998. Role of the ZWILLE gene in the regulation of central shoot meristem cell fate during Arabidopsis embryogenesis. EMBO J. 17: 1799-1809.

Müller, B. and Sheen, J. 2007. Advances in cytokinin signaling. Science 318: 68-69.

Nakayama, T., Nishioka, K., Dong, Y.X., Shimojima, T., and Hirose, S. 2007. Drosophila GAGA factor directs histone H3.3 replacement that prevents the heterochromatin spreading. Genes Dev. 21: 552-561.

Ori, N., Eshed, Y., Chuck, G., Bowman, J.L., and Hake, S. 2000. Mechanisms that control knox gene expression in the Arabidopsis shoot. Development 127: 5523-5532.

Pautot, V., Dockx, J., Hamant, O., Kronenberger, J., Grandjean, O., Jublot, D., and Traas, J. 2001. KNAT2: Evidence for a link between knotted-like genes and carpel development. Plant Cell 13: 1719-1734.

Phelps-Durr, T.L., Thomas, J., Vahab, P., and Timmermans, M.C. 2005. Maize rough sheath2 and its Arabidopsis orthologue ASYMMETRIC LEAVES1 interact with HIRA, a predicted histone chaperone, to maintain knox gene silencing and determinacy during organogenesis. Plant Cell 17: 2886-2898.

Pien, S. and Grossniklaus, U. 2007. Polycomb group and trithorax group proteins in Arabidopsis. Biochim. Biophys. Acta 1769: $375-382$.

Pietersen, A.M. and van Lohuizen, M. 2008. Stem cell regulation by polycomb repressors: Postponing commitment. Curr. Opin. Cell Biol. 20: 201-207.

Prigge, M.J., Otsuga, D., Alonso, J.M., Ecker, J.R., Drews, G.N., and Clark, S.E. 2005. Class III homeodomain-leucine zipper gene family members have overlapping, antagonistic, and distinct roles in Arabidopsis development. Plant Cell 17: 61-76.

Ray-Gallet, D., Quivy, J.P., Scamps, C., Martini, E.M., Lipinski, M., and Almouzni, G. 2002. HIRA is critical for a nucleosome assembly pathway independent of DNA synthesis. Mol. Cell 9: 1091-1100.

Reinhardt, D., Mandel, T., and Kuhlemeier, C. 2000. Auxin regulates the initiation and radial position of plant lateral organs. Plant Cell 12: 507-518.

Reinhardt, D., Frenz, M., Mandel, T., and Kuhlemeier, C. 2003a. Microsurgical and laser ablation analysis of interactions between the zones and layers of the tomato shoot apical meristem. Development 130: 4073-4083.

Reinhardt, D., Pesce, E.R., Stieger, P., Mandel, T., Baltensperger, K., Bennett, M., Traas, J., Friml, J., and Kuhlemeier, C. 2003 b. Regulation of phyllotaxis by polar auxin transport. Nature 426: 255-260.

Reiser, L., Sánchez-Baracaldo, P., and Hake, S. 2000. Knots in the family tree: Evolutionary relationships and functions of knox homeobox genes. Plant Mol. Biol. 42: 151-166.

Sablowski, R. 2007. The dynamic plant stem cell niches. Curr. Opin. Plant Biol. 10: 639-644.

Sakamoto, T., Kamiya, N., Ueguchi-Tanaka, M., Iwahori, S., and Matsuoka, M. 2001. KNOX homeodomain protein directly suppresses the expression of a gibberellin biosynthetic gene in the tobacco shoot apical meristem. Genes Dev. 15: 581-590.

Scanlon, M.J., Henderson, D.C., and Bernstein, B. 2002. SEMAPHORE1 functions during the regulation of ancestrally dupli- 
cated knox genes and polar auxin transport in maize. Development 129: 2663-2673.

Scheres, B. 2007. Stem-cell niches: Nursery rhymes across kingdoms. Nat. Rev. Mol. Cell Biol. 8: 345-354.

Schneeberger, R., Tsiantis, M., Freeling, M., and Langdale, J.A. 1998. The rough sheath 2 gene negatively regulates homeobox gene expression during maize leaf development. Development 125: $2857-2865$.

Schoof, H., Lenhard, M., Haecker, A., Mayer, K.F., Jürgens, G., and Laux, T. 2000. The stem cell population of Arabidopsis shoot meristems is maintained by a regulatory loop between the CLAVATA and WUSCHEL genes. Cell 100: 635-644.

Schubert, D., Primavesi, L., Bishopp, A., Roberts, G., Doonan, J., Jenuwein, T., and Goodrich, J. 2006. Silencing by plant Polycomb-group genes requires dispersed trimethylation of histone $\mathrm{H} 3$ at lysine 27. EMBO J. 25: 4638-4649.

Schwartz, Y.B. and Pirrotta, V. 2007. Polycomb silencing mechanisms and the management of genomic programmes. Nat. Rev. Genet. 8: 9-22.

Scofield, S. and Murray, J.A. 2006. KNOX gene function in plant stem cell niches. Plant Mol. Biol. 60: 929-946.

Semiarti, E., Ueno, Y., Tsukaya, H., Iwakawa, H., Machida, C., and Machida, Y. 2001. The ASYMMETRIC LEAVES2 gene of Arabidopsis thaliana regulates formation of a symmetric lamina, establishment of venation and repression of meristemrelated homeobox genes in leaves. Development 128: $1771-1783$.

Sharp, J.A., Fouts, E.T., Krawitz, D.C., and Kaufman, P.D. 2001 Yeast histone deposition protein Asflp requires Hir proteins and PCNA for heterochromatic silencing. Curr. Biol. 11: 463 473.

Shibahara, K. and Stillman, B. 1999. Replication-dependent marking of DNA by PCNA facilitates CAF-1-coupled inheritance of chromatin. Cell 96: 575-585.

Shuai, B., Reynaga-Peña, C.G., and Springer, P.S. 2002. The lateral organ boundaries gene defines a novel, plant-specific gene family. Plant Physiol. 129: 747-761.

Song, S.K., Lee, M.M., and Clark, S.E. 2006. POL and PLL1 phosphatases are CLAVATA1 signaling intermediates required for Arabidopsis shoot and floral stem cells. Development 133: 4691-4698.

Spector, M.S., Raff, A., DeSilva, H., Lee, K., and Osley, M.A 1997. Hirlp and Hir2p function as transcriptional corepressors to regulate histone gene transcription in the Saccharomyces cerevisiae cell cycle. Mol. Cell. Biol. 17: 545-552.

Stuurman, J., Jäggi, F., and Kuhlemeier, C. 2002. Shoot meristem maintenance is controlled by a GRAS-gene mediated signal from differentiating cells. Genes Dev. 16: 2213-2218.

Tagami, H., Ray-Gallet, D., Almouzni, G., and Nakatani, Y. 2004 Histone H3.1 and H3.3 complexes mediate nucleosome assembly pathways dependent or independent of DNA synthesis. Cell 116: 51-61.

Theodoris, G., Inada, N., and Freeling, M. 2003. Conservation and molecular dissection of ROUGH SHEATH2 and ASYMMETRIC LEAVES1 function in leaf development. Proc. Natl. Acad. Sci. 100: 6837-6842.

Timmermans, M.C., Hudson, A., Becraft, P.W., and Nelson, T. 1999. ROUGH SHEATH2: A Myb protein that represses knox homeobox genes in maize lateral organ primordia. Science 284: $151-153$.

Tsiantis, M., Schneeberger, R., Golz, J.F., Freeling, M., and Langdale, J.A. 1999. The maize rough sheath2 gene and leaf development programs in monocot and dicot plants. Science 284: $154-156$.

Tucker, M.R. and Laux, T. 2007. Connecting the paths in plant stem cell regulation. Trends Cell Biol. 17: 403-410.

Tucker, M.R., Hinze, A., Tucker, E.J., Takada, S., Jürgens, G., and Laux, T. 2008. Vascular signalling mediated by ZWILLE potentiates WUSCHEL function during shoot meristem stem cell development in the Arabidopsis embryo. Development 135: 2839-2843.

Turck, F., Roudier, F., Farrona, S., Martin-Magniette, M.L., Guillaume, E., Buisine, N., Gagnot, S., Martienssen, R.A., Coupland, G., and Colot, V. 2007. Arabidopsis TFL2/LHP1 specifically associates with genes marked by trimethylation of histone $\mathrm{H} 3$ lysine 27. PLoS Genet. 3: e86.

van den Berg, C., Willemsen, V., Hendriks, G., Weisbeek, P., and Scheres, B. 1997. Short-range control of cell differentiation in the Arabidopsis root meristem. Nature 390: 287-289.

Vollbrecht, E., Reiser, L., and Hake, S. 2000. Shoot meristem size is dependent on inbred background and presence of the maize homeobox gene, knotted1. Development 127: 31613172 .

Williams, L. and Fletcher, J.C. 2005. Stem cell regulation in the Arabidopsis shoot apical meristem. Curr. Opin. Plant Biol. 8: 582-586.

Williams, L., Grigg, S.P., Xie, M., Christensen, S., and Fletcher, J.C. 2005. Regulation of Arabidopsis shoot apical meristem and lateral organ formation by microRNA miR166g and its AtHD-ZIP target genes. Development 132: 3657-3668.

Wu, X., Dabi, T., and Weigel, D. 2005. Requirement of homeobox gene STIMPY/WOX9 for Arabidopsis meristem growth and maintenance. Curr. Biol. 15: 436-440.

Würschum, T., Gross-Hardt, R., and Laux, T. 2006. APETALA2 regulates the stem cell niche in the Arabidopsis shoot meristem. Plant Cell 18: 295-307.

Yanai, O., Shani, E, Dolezal, K., Tarkowski, P., Sablowski, R. Sandberg, G., Samach, A., and Ori, N. 2005. Arabidopsis KNOXI proteins activate cytokinin biosynthesis. Curr. Biol. 15: $1566-1571$.

Zhang, R., Poustovoitov, M.V., Ye, X., Santos, H.A., Chen, W., Daganzo, S.M., Erzberger, J.P., Serebriiskii, I.G., Canutescu, A.A., Dunbrack, R.L., et al. 2005. Formation of MacroH2Acontaining senescence-associated heterochromatin foci and senescence driven by ASF1a and HIRA. Dev. Cell 8: 19-30.

Zhang, X., Germann, S., Blus, B.J., Khorasanizadeh, S., Gaudin, V., and Jacobsen, S.E. 2007. The Arabidopsis LHP1 protein colocalizes with histone H3 Lys27 trimethylation. Nat. Struct. Mol. Biol. 14: 869-871.

Zhang, Z., Shibahara, K., and Stillman, B. 2000. PCNA connects DNA replication to epigenetic inheritance in yeast. Nature 408: 221-225.

Zhao, Y., Medrano, L., Ohashi, K., Fletcher, J.C., Yu, H., Sakai, H., and Meyerowitz, E.M. 2004. HANABA TARANU is a GATA transcription factor that regulates shoot apical meristem and flower development in Arabidopsis. Plant Cell 16: 2586-2600. 


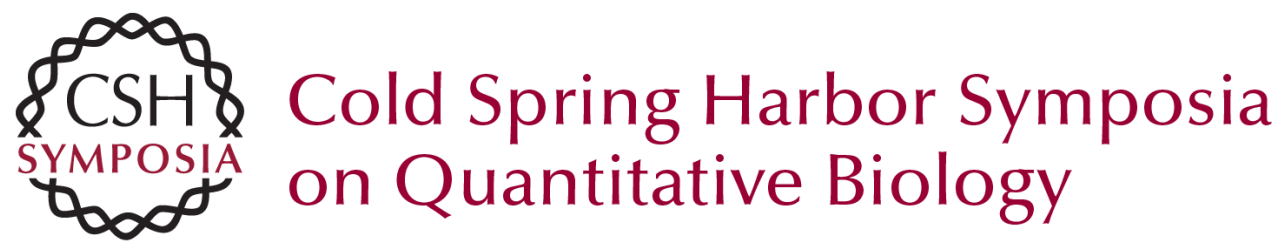

\section{Genetic and Epigenetic Regulation of Stem Cell Homeostasis in Plants}

M. Lodha, C.F. Marco and M.C.P. Timmermans

Cold Spring Harb Symp Quant Biol 2008 73: 243-251 originally published online January 15, 2009 Access the most recent version at doi:10.1101/sqb.2008.73.044

References This article cites 100 articles, 46 of which can be accessed free at: http://symposium.cshlp.org/content/73/243.full.html\#ref-list-1

\section{License}

Email Alerting Receive free email alerts when new articles cite this article - sign up in the box at the Service top right corner of the article or click here. 